Tottva, Vol. 2, No. 2, July - December 2010, pp. 54-60 ISSN 0975-332X | https://doi.org/10.12726/tjp.4.5

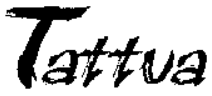

JOURNAL OF PHILOSOPHY

\title{
GOD BEYOND THE GARDEN OF NAMA- RUPA: AN INDIAN ROSETTA STONE FOR REFRAMING WESTERN METAPHYSICS
}

\author{
Barbara A. Amodio, Ph.D.
}

Albert Einstein persevered to the last moment of his life, the only monotheist among his colleagues, believing that the cosmos is fundamentally organic, orderly and coherent, questing for a unified mathematical expression for the theory of relativity. He once quipped to Quantum theorists, satisfied with randomness and two disjunctive theories, that God did not play dice. Covering his bed linens with formulae, he struggled with the oars of discursive reason to find a mathematical parameterization of the total cosmos. He had no benefit of Vedic and Upanisadic wisdom regarding the technical manifestation of maya and its ethical and metaphysical roles, nor the precise articulation in the Tantra Sastras of five pure and thirty-one impure Tattwas or modalities in a continuum of evolution in cosmic consciousness in parallel vibrations of sound and light, nor even Krisna's summary remarks to Arjuna in Gita 9.4 regarding the mystery of the Cosmic God's connection and manifestation as the gross, appearing, created world. He did not regard meditation as the only way to know the way that mystery. He was not armed with the Indian tradition's careful analyses of the limits of discursive expression tools of which language and mathematical sentences are but two examples. Einstein exhausts himself. His nurse coaxes books and pens from his fingers and inquires what Herr Professor has been doing so long and with such intensity. She might have asked what most of western metaphysics, misreading the Greeks without the backdrop of the Indian tradition, has been doing so long and with such exhausting intensity. 
His reply to the nurse is elegant, instructive and unifying for process philosophers and contemplatives alike. He confides that he has been trying to find God, indeed, he has spent his whole life chasing God, but has not been able to catch him. Perhaps, Herr Professor, she will suggest, you could try to find him again tomorrow after a good night's rest, in the garden where you like to work. Perhaps, she suggests, he is the gardener and you can talk to him. Fatigued and yielding to her, he replies: The gardener...I think $\mathrm{He}$ is the garden.

Einstein's insight and Whitehead's, point to the intimate and responsive closeness, accessibility, experiential and relational presence of God in the knots of the appearing gardens of maya, but never get beyond the densely woven strands of the appearing, existential weave of Maya and Nama-Rupa. Neither Einstein, nor Whitehead, nor most of western metaphysics, ever completely or adequately transcends the garden, mostly owing to a near-exclusive reliance on discursive expressive tools, and other failures associated with the lack of development of a full, technical and complementary fluency in the non-discursive language more common to developed world traditions of the ascetic's Inner Way.'

The full technical vocabulary and navigation chart for a precise journey beyond the garden is best preserved in the rich and ancient complexity and dialogue in the Indian Samkhya-Yoga and closely allied Sufi traditions of the Inner Way, illustrated in the parallel cosmologies of sound and light in the Tantra Sastras of SaivaSaktism, without which the unified cosmos beyond the appearing garden of maya cannot be known or fully articulated. The traditional jnana yoga emphases of logic and discursive examination have been cut loose in the west from their primary mooring in meditative consciousness, losing the connection of theoria derived from theos (godly) and its implication of a more Indian direct seeing and experiencing of divinity. The contemplatives' tool for transit is Consciousness in all its modality, and I will join with the late and eminent John Britto Chethimattam in laying radical emphasis on Consciousness as the great unifying gift of the Indian tradition to the metaphysical world, making it the ultimate monism of substance and the atomic building block of the cosmos. ${ }^{2}$ The real atom is the atom point of

1. The parallels and dialogue between Sufi and Indian traditions of the Inner Way (Tasamwuf) are discussed elsewhere. See Amodio, Barbara A. Unifying the Heart Locus and Expanding the Gemstone in the Ocean of Consciousness: Unifying the Islamic and Indian Tradition Perspectives on the Inner Woy. Written for the lbn 'Arabi Society and the Journal of the Muhyiddin Ibn 'Arabi Society, delivered at the $20^{\text {th }}$ Annual USA Symposium, The Faculty Club, University of California at Berkeley, Oclober 2007. (Available from the Ibn Arabi Society, Oxford and The Center for Process Sludies, Claremont, CA)

2. See especially Chethimattam's Consciousness and Reality, Dialogue in Indian Iradition and Philosophy As Experience for this perceptive understanding of the modalities and monism of Consciousness grounding the rich complexity of the Indian fradition from ancient to modern 
consciousness from particular to universal, from gross to concrescently subtle to Primordial, threading through the many unto the One. Everything, then, is Consciousness under modality, a living, precisely projected dreamstuff, ${ }^{3}$ better nuanced by Ramanuja than Samkara for the discerning reader. A thoroughgoing, non-discursive raja yoga journey is required to supply the navigation charts for a safe and efficient voyage into the depths of the Vedic Ocean of Consciousness when sight of shore is lost. This is a journey into the depths of the cosmos without need for a particle accelerofor, nor any other equipment than the quiet and stilled mind. A boat of contemplative method is required such that the contemplative navigations associated with the religions of the world constitute the sensitive nadis and marmas, or meridians and acupuncture points, by which entry into the Ocean of Oneness is made. They provide the visas and passports for the deep journey, and none beffer nor more completely conserved than in the Yoga and Sufi charts, though anyone caught at sea, even in a western monastery, will be able to discover pieces of the chart albeit without the important warnings and more careful, efficient guidance that would otherwise be available.

Whitehead's system, reframed within the Indian systems selected, rightly finds a set of shifted and amplified meanings that expose hidden and unitying equivalences of Greek and Indian metaphysics, including the Pythagorean pi harmonic and the complex AUM varnamala as chords on which to fly out of the real cave of the human body on a rocket of sacred sound and light in the hidden Golden Section of the soul line in disciplined meditative consciousness, threading with precision along a definite trajectory through the subtle formal background of sphota and nama-rupa beyond the garden, through the Tattwas, where Platonic Form is at home in Indian subfle modal consciousness, all invisible to the senses, flying on the compass of the sincere heart in subservience and love for the Awesome One and Creator, journeying progressively from saguna to nirguna Brahman. ${ }^{4}$

limes. His identification and scholarly drawing out of the lacit implications of Consciousness provides a great service to metaphysicions everywhere and to the Indian tradition.

3. See olso Amodio, Barbara A. The Field As Dreamscape: The Hallucinotion of Perception, Waking and Dreamless Sleep. Invited paper and selection for the inaugural issue of the International Journol of Field-Being (IFB), July 2000. Delivered 16 July 1998 at Fairfield University, Fairfield, CT (USA) (Available at Center for Process Studies, Cloremont, CA) Essenlially a comparative study of the four states articulated in the Mandukhya Upanishad with a view toward their modern corroborations in NLP's original formulation by Lozanov of NLP (Neurolinguistic Programming) data. A radical view of Reality as ultimately Cosmic Consciousness at all levels of manifestalion is assumed throughout. See also Amodio, Barbaro A. Aesthetic Evolution: Value, Meaning and the Interplay of Opposites with Speciol Reference to Process Philosophy, Romanuja and the Tao-te Ching. Invited paper for the Third Int'l Symposium of Field-Being, Foirtield University, Fairfield, CT (USA.) August 12-17, 1999. IIFB Journal 1999. (Available at The Center for Process Studies, Claremont, CA.)

4. Read Brohman as a functional equivalent of Allah, the Tao, To On, the One, and so on. 
Correctives to Whitehead's problems with the One and the many emerge, and I will join Robert C. Neville in his apt criticism of deficiencies of the Whiteheadean One, ${ }^{5}$ relocating it as an instance of Brahma, even lsvara, but not the Non-Dual Oneness of Brahman that is required for a full metaphysics. The cool water of meditation takes down the heat of the mindstuff (manas) in the manner prescribed by Patanjali and its modern Kriya-Yoga schools, attenuating the ripples in the internal pool of the individual mind, gradually destroying the fructifying and even the unfructifying karmas in a matrix where human personality and identity extend beyond the present lifetime. Expansion of the Whiteheadean circumscription of the person as a nest of internally determined and externally free prehensions illustrates the precise weave of three technical karmas on each person, amplifying the metaphysical and ethical meaning in the Whiteheadean emotional satisfactions captured in the continuum of past-present-future projections in the constitution of the privacy ${ }^{6}$ of a personal event-nexus. As the highly agitated ripples in the ordinary overheated and distracted monkey mind are gradually tamed and cooled in the journey toward Equipoise and harmonic stillness in the Non-Dual One, we enter the progressive lack of differentiation and wavelike loss of identity of the BoseEinstein condensate, and connect the yogi's journey without a particle accelerator or absolute freezing to the cosmology of Cosmic Consciousness. Heraclitus, Einstein, and Whitehead meet Pythagorus, Plato, Bose, and the Rsis as process and stillness fit together in the necessary paradox of Samkhya-Yoga. ${ }^{7}$ For this has Valmiki told us Rama's favorite season is winter in the high Himalayas.

The Indian tradition, particularly the Hindu-Christian dialogue, and the deep and ancient dialogue on Indian soil among revealed traditions, provides a true philosophical Rosetta Stone for decoding, penetrating and unifying systematic metaphysics across world traditions. True metaphysics cannot be performed without it. To date, the process community, which is at least admirably committed to interactive dialogue at all levels, has explored a Rosetta Stone for decoding the metaphysical and ethical dramas of lived experience etched in comparatively few world metaphysical scripts, chiefly Taoism and certain Buddhisms. Both these traditions, while enormously instructive, lack sufficient detail regarding the articulate structures of cosmic Background modality and the phenomenology of consciousness implied,

5. See Neville's recent article in The Journal of Process Studies, August 2008, as also his God the Creator, and The Too and the Daemon, for perspicacious articulations of deficiencies of Whitehead's One, and critical articulations of speculative metaphysical positions of many Chinese traditions in process dialogue.

6. Privacy should be read in the way the late Paul Weiss developed it as a Whiteheadean melaphor in Privacy and Modes of Thought, and throughout his work.

7. Offen misread by scholors as a dualism, Samkhya-Yoga operates from a monism of substance where the substance is consciousness, at rest or in musical motions, knowable as continuous only in meditation. 
and important features of the Pyramid Texts cannof be deciphered. We will identify and briefly discuss errors and omissions in these and in western metaphysical scripts generally, while showing that without the Hindu script there will be no full reading of the real and unifying metaphysical mosaic and prism close at hand. The Indian Rosetta Stone, chiseled with the meticulous detail and precision of the ancient Harrappan engraver, remains largely neglected and undecipherable for western metaphysics beyond a few favorite and superficial remarks about Samkara, neglecting Ramanuja's subtlety. The new Rosetta Stone proposed, unlike its Egyptian counterpart, is worked in at least four and probably eight distinct, systematically developed world metaphysical languages and sacred aesthetic artifacts rooted in Indian soil: Hindu, Sufi, Graeco-Bactrian-Mauryan-Pythagorean, Celtic-IndoAryan $^{8}$, Buddhist-Jain-Sikh, Muslim and Code Hammarabi, and Dravidian-ProtoIndo-Mediterranean (including Egyptian.)

Going back to times before continents sunk into the Indian Ocean and plains flooded to create the Mediterranean, an ancient cultural integrity prevailed that is now fragmented, at least for the west, though still accessible by archaeological, comparative culture and comparative mythology reconstructions, constituting a vast and instructive topic for another Proto-Indo-Mediterranean forum of discussion. Simply said for the present, this article assumes an Indian perspective on the Greeks, and seriously values neglected aspects of the Hindu-Sufi-Christian dialogue, thinking the religion that the world lately calls Christianity is in very serious ways much older and rooted in India's indigenous ascetic heritage, in intense dialogue with the highly developed Hindu and Sufi ascetic traditions. Taoism, indigenous to China, makes a quantum leap over the important terrain of subtle background, and Buddhisms variously falter in a phenomenology of consciousness that fails to discriminate the fully emptied buddhi from the abiding atman, leading to the radical process that tempts process philosophers and lures them to remain in the relational weave of the garden without $a$ soul, shored up by a misplaced abstraction regarding the momentariness of phenomenological articulations of attention in the mindstuff (manas) that obstructs a full launch out of the garden and impedes recovery of the garden as in any way a beautiful, just, good and true aspect of God's Cosmic Body. Here, reframing Whitehead's God and cosmology, adding the neglected ingredient of the disciplined restraint of consciousness in meditation illustrated by Patanjali, the connection between human consciousness and cosmic consciousness is restored in all its full detail, and with it the Bergsonian and Plotinian continuum of the garden with subtle and Supreme cosmic consciousness. The three modalities

8. Evidence is currently being reconstructed regarding the Greek and Drovidian contributions. The archaeological evidence for the ancient European and meditative Aryan connections is scaltered throughout Europe, and mythology suggests evidence in the permofrost. This is a topic for another place. 
revealed bear uncanny resemblance to the Whiteheadean Primordial to concrescent to consequent trajectory reframed now as Supreme (Para) to subtle (suksma) to gross (sthula.)

It is no accident that Whitehead lays down his set theory in Part IV of Process and Reality to parameterize the Coordinate Division that expresses the gross, consequent, existential modality of cosmic consciousness. We need to build the missing section on the Eternal Objects in subfle concrescence beyond the garden and closely associate it with Whitehead's peculiar mathematical topography in an Indian manner. A reflecting pool, a black Taj Mahal, unfinished in India as in Whitehead, is needed to communicate propositionally with the white Toj Mahal that stands in the gross, existential weave of the garden. In this black, invisible building and its concrescently subtle pool is a hidden Hindu and Graeco-Bactrian-MauryanPythagorean dialogue that connects the Euclidean and Pythagorean uses of the point to Whitehead's definition of abstractive hierarchies evolved to punctual (point) stolus, then used as overpaint for the gross, appearing, existential world of moya ${ }^{9}$, making it pop or project into gross appeorance. An Indo-Greek perspective on Whitehead's mathematics is possible that re-establishes the inherent compatibility of the necessary paradoxical togetherness of motion and rest. Our goal will be to reconnect the Whiteheadean emphasis on Heraclitus and Einstein to Pythagorean ascetic insights and the record of mysticism left in Yoga-Samkhya and Tantric schools of Saiva-Saktism. ${ }^{10}$ At the heart of this mathematics emerges the real elliptical theatre of cosmic and ethical tragedy, comedy and melodrama in the preferences of Whitehead, the Greeks and the Indians for the rolling mathematical planes of cones, ellipses, ovate classes and circles for which we will supply a sacred texture.

9. These notions are developed in on earlier aesthelic transtation of Whitehead's sel theory, where punciual status denofes an abstractive hierarchy evolved to the slatus of a nonsubstontial, qualitative point without ports, and overpaint stands for the situation where abstractive hierarchies cover each other without inclusion in each other's infernol abstractive hierarchies, enabling elernal, or betfer, concrescently subtle sphofons, to appear or project as Maya. Background and Foreground are introduced to simplify the appearing and disappearing modalities of the cosmic continuum. See Parl 1 of Amodio, Barbora A. Quolity and Reality: A Pythagorean-Whiteheadean Redefinition of the Existential Mode of Appearance. Fordhom University and University Microfilms, Ann Arbor, Ml:1979 (\& Center for Process Studies, Claremont, CA)

10. It is no accident that the Saiva-Saktism and ancient Tantro Sastras are recoverable in the unique dialogue between Yoga-Samkhya schools and predominately Muslim areas of India. This is a neglected dialogue addressed partially in the Introduction and throughout of my remarks to the Muhyiddin Ibn 'Arabi Society mentioned above. The Sufi dialogue of Chishti and Naqshbandi should be carefully reconstructed through its Indian, Bactrion and Afghani soils. 
The journey within and out of the process garden involves an appearing foreground and a non-appearing background that are a continuum. The journey into background requires the disciplined used of meditalive consciousness as meticulously described by Patanjali and the Yoga-Samkhya Schools, and the Tantra Sastras, covertly conserved in ascetic schools, and transmitted and trained by the supremely realized guru, master or pir. In this journey the Rsis and the Indo-Greeks shine brightly and many ancient Sufi stars are polished jewels in a unified sky of Spirit and Word. We will go as for as permissible in language and public writing to articulate a unified position. 